\title{
Anxiogenic-like effect of acute and chronic fluoxetine on rats tested on the elevated plus-maze
}

M.T.A. Silva,

C.R.R. Alves and

E.M.M. Santarem

\author{
Departamento de Psicologia Experimental, \\ Instituto de Psicologia, Universidade de São Paulo, \\ São Paulo, SP, Brasil
}

\section{Correspondence \\ M.T.A. Silva \\ IPUSP \\ Av. Prof. M ello Moraes, 1721 \\ 05508-900 São Paulo, SP \\ Brasil \\ Fax: + 55-11-818-4357 \\ E-mail: teresar@usp.br \\ Publication supported by FAPESP. M.T.A. Silva was the recipient of a CNPq fellowship (N o. 520591/96-8). \\ C.R.R. Alves was the recipient of a Master's fellowship from FAPESP (No. 96/0354-0). E.M.M. Santarem was the recipient of a $\mathrm{CNPq}$ post-doctoral fellowship (No. 301587/92).}

Received June 24, 1998 Accepted November 19, 1998

\section{Abstract}

The selective serotonin reuptake inhibitor fluoxetine (FLX) is widely prescribed for depression and anxiety-related disorders. On the other hand, enhanced serotonergic transmission is known to be classically related to anxiety. In this study, the effects of acute $(5.0 \mathrm{mg} / \mathrm{kg})$ and chronic $(5.0 \mathrm{mg} / \mathrm{kg}, 22$ days) FLX were investigated in both fooddeprived and non-deprived rats tested in the elevated plus-maze. Significant main effects of the three factors (drug, food condition and administration regimen) were observed, but no interaction between them. The administration of either acute or chronic FLX resulted in an anxiogenic effect, as detected by a significant reduction in the percentage of time spent in the open arms and in the percentage of open arm entries. Food deprivation yielded an anxiolytic-like profile, probably related to changes in locomotor activity. The administration regimen resulted in an anxiolytic profile in chronically treated rats, as would be expected after 22 days of regular handling. The anxiogenic action of acute FLX is consistent with both its neurochemical and clinical profile. The discrepancy between the anxiogenic profile of chronic FLX and its therapeutic uses is discussed in terms of possible differences between the type of anxiety that is measured in the plus-maze and the types of human anxiety that are alleviated by fluoxetine.
Key words

- Elevated plus-maze

- Fluoxetine

- Anxiety

- Handling

- Food-restriction

\section{Introduction}

Besides being one of the most widely prescribed drugs for depression, fluoxetine (FLX) is also used for anxiety-related disorders such as obsessive-compulsive disorder, panic, social phobia and bulimia nervosa (15). However, the classic hypothesis relating increased serotonergic function to anxiety $(6,7)$ predicts that fluoxetine, a selective serotonin reuptake inhibitor (SSRI), would pro- voke an anxiogenic effect when tested on animal models. After acute administration, there is an increase in extracellular serotonin in several subcortical brain regions due to reuptake blockade $(8,9)$. Although this extracellular 5-HT seems to inhibit the firing of raphe neurons and thus to reduce 5-HT release from nerve terminals (9), it is often reported that the initial effect of fluoxetine administration in humans is an exacerbation of anxiety $(10,11)$, and this effect has been 
related to the sharp increase in synaptic serotonin concentrations after acute administration of the drug $(7,12)$. During chronic administration there is an increase of extracellular concentrations of 5-HT at cortical and subcortical levels, and the long-term 5-HT reuptake blockade provokes desensitization of somatodendritic 5- $\mathrm{HT}_{1 \mathrm{~A}}$ and terminal 5$\mathrm{HT}_{1 \mathrm{~B}}$ autoreceptors, respectively leading to a disinhibitory effect on raphe neurons firing and to reduced feedback inhibition of 5-HT release (13-15). Both of these neuroadaptive changes lead to enhanced serotonergic release and transmission $(16,17)$.

However, the data obtained in animal studies using SSRI antidepressants are contradictory $(12,18,19)$. Specifically, the evidence of the effect of fluoxetine on animal models of anxiety is controversial, and studies on its chronic effects are scarce. Acute fluoxetine has been shown to promote anxiogenic-like effects in rats tested in the elevated plus-maze (20-22), in the hole-board (20), and in a light-aversion test (20). The same effects are observed in the noveltysuppressed feeding model of anxiety (23) and in the antipredator defensive behavior of mice (24). Vogel's conflict test (22), however, yielded anxiolytic-like effects in rats, and so did another light aversion test (25). Effects of the same nature, albeit weak, were reported for the shock-induced ultrasonic vocalization test in rats $(19,26)$. Chronic administration of fluoxetine also suggests an anxiolytic effect of the drug, since it has been reported to "dramatically" decrease flight reactions and defensive attack towards a predator (24) and to reduce latency to begin eating in a novel environment (23). On the other hand, some studies have reported the absence of either an anxiogenic or an anxiolytic effect of the drug, administered acutely or chronically. For example, acute fluoxetine was inactive in a light aversion test $(19,27)$ and in the plus-maze $(28,29)$. When administered chronically at the dose of $10 \mathrm{mg} / \mathrm{kg}$, it had no effect on a condi- tioned-fear stress test (30).

The elevated plus-maze is a widely used animal model of anxiety involving unconditioned responses based on exploration. Although an anxiogenic effect or a lack of effect of acute fluoxetine has been found in some of the studies using the elevated plusmaze, the chronic effect of the drug on this model has not been investigated. The present experiment was conducted in order to examine the effect of both acute and chronic fluoxetine on the elevated plus-maze. A possible interaction with food deprivation was also investigated, since a differential effect of acute versus chronic fluoxetine has been reported in a model of anxiety that relies on food deprivation (23).

\section{Material and Methods}

\section{Subjects}

The subjects were 94 experimentally naive male Wistar rats weighing approximately $300 \mathrm{~g}$ at the beginning of the experiment. They were singly housed in $24.0 \times 17.5 \mathrm{x}$ 19.0-cm metal cages and were maintained on a 12-h dark-light cycle (lights on at 7:00 h) in a temperature- $\left(22 \pm 2^{\circ} \mathrm{C}\right)$ and humidity- $(55 \% \mathrm{RH})$ controlled environment. Half of the subjects were maintained at $80 \%$ of their free-feeding body weight, whereas the other half had free access to standard rodent lab food. Water was always available. Animals were weighed every day except on weekends.

\section{Apparatus}

A standard wooden plus-maze apparatus consisting of $50 \times 10 \times 40-\mathrm{cm}$ opposite closed arms and $50 \times 10-\mathrm{cm}$ open arms that radiated from a central $10 \times 10-\mathrm{cm}$ space was used. The apparatus was elevated to a height of 50 $\mathrm{cm}$ above floor level by a single support. The open arms were surrounded by a $1-\mathrm{cm}$ translucid Plexiglas ledge, and a dim white 
light $(15 \mathrm{~W})$ placed $90 \mathrm{~cm}$ above the central area was the only source of illumination.

\section{Procedure}

Experiments were carried out between 9:00 and 17:00 h. Animals were randomly assigned to two groups, fluoxetine (FLX, N $=46)$ and vehicle (VEH, $\mathrm{N}=48)$. The drugs were administered either acutely or chronically. In each of these conditions animals were either food deprived or fed ad libitum. Thus, FLX and VEH subjects were divided into 4 subgroups $(\mathrm{N}=11-13$ each): food deprived under acute treatment, food deprived under chronic treatment, satiated under acute treatment and satiated under chronic treatment. The eight groups were submitted to the behavioral procedure in alternate order, so as to counterbalance possible sequence effects.

Each subject was placed in the central area of the maze facing one of the closed arms, either $60 \mathrm{~min}$ after the first injection (acute treatment) or $60 \mathrm{~min}$ after the 22nd injection (chronic treatment) of fluoxetine or vehicle, in alternate order. Animals were observed for $5 \mathrm{~min}$ by a trained observer who sat quietly $1.5 \mathrm{~m}$ from the center of the maze and recorded the time spent in and the number of entries into each arm. An entry was recorded when the animal's four limbs had entered an arm. The observer was "blind" to the animal's condition.

\section{Drugs}

Fluoxetine hydrochloride (Lilly, São Paulo, SP, Brazil) was dissolved in Tween80 plus $0.9 \% \mathrm{NaCl}$. Daily ip injections of $5 \mathrm{mg} / \mathrm{kg}$ were administered for 22 days, at the same time each day, in the chronic treatment subjects. Rats in the acute treatment groups received the same dose but only once. The corresponding treatment was given to the animals in the control group, which received vehicle injections $(0.9 \% \mathrm{NaCl}$ and
Tween-80). All injections were performed in a different room from that of the plusmaze testing. The drug dosage was selected on the basis of its effectiveness on chronic behavioral procedures such as polydipsia (31) and stress-induced anhedonia (32).

\section{Data analysis}

For each animal, the percent of time spent in the open arms (100 x open/(open + closed)), the percent of open arm entries (100 x open/total), the number of entries into the closed arms and the total number of entries (open + closed arms) were computed. Data were analyzed by a three-factor (drug, treatment regimen, and food condition) analysis of variance, with two levels for each factor (FLX $x$ VEH; chronic $x$ acute; satiated $\mathrm{x}$ deprived).

\section{Results}

Analysis of variance showed that there were no 2-way or 3-way significant interactions between factors. Since 3-way and 2way interactions were not significant, main effects were analyzed. The results are summarized in Figure 1.

There was a significant main effect of drug condition. Fluoxetine decreased the percentage of time spent in the open arms $(F(1,86)=9.825, P<0.01)$, the percentage of open arm entries $(\mathrm{F}(1,86)=6.884, \mathrm{P}<0.01)$, total arm entries $(\mathrm{F}(1,86)=18.112, \mathrm{P}<0.001)$ and number of entries into the closed arms $(F(1,86)=11.085, P<0.001)$. This main effect is shown in Figure 1, where it can be seen that the FLX group means are lower than the VEH group means in all comparisons. This effect occurred independently of alimentary condition or treatment regimen.

The ANOVA also revealed a significant main effect of food condition: food deprivation increased the percentage of time spent in the open arms $(\mathrm{F}(1,86)=76.593, \mathrm{P}<0.001)$, the proportion of open arm entries $(\mathrm{F}(1,86)=$ 
41.293, $\mathrm{P}<0.001)$, total arm entries $(\mathrm{F}(1,86)$ $=39.316, \mathrm{P}<0.001)$ and the number of entries into the closed arms $(\mathrm{F}(1,86)=12.432$, $\mathrm{P}<0.001)$. This effect occurred whether the animals received fluoxetine or vehicle, either acutely or chronically.

Furthermore, ANOVA revealed a sig-

Figure 1 - Effect of fluoxetine on rats tested on the elevated plusmaze. Percent time spent in the open arms, percent entries into the open arms, total number of entries and number of entries into the closed arms are given for the eight groups in the experiment. "Administration regimen" (acute x chronic) and "food condition" (food deprived $x$ satiated) are plotted as a function of the "drug" factor (fluoxetine $x$ vehicle). Significance levels as revealed by a 3-factor ANOVA are shown in the text. Data are reported as means \pm SEM. FLX = Fluoxetine, VEH = vehicle, $\mathrm{Ac}=$ acute, $\mathrm{Ch}=$ chronic, Dep $=$ food deprived, Sat $=$ satiated.
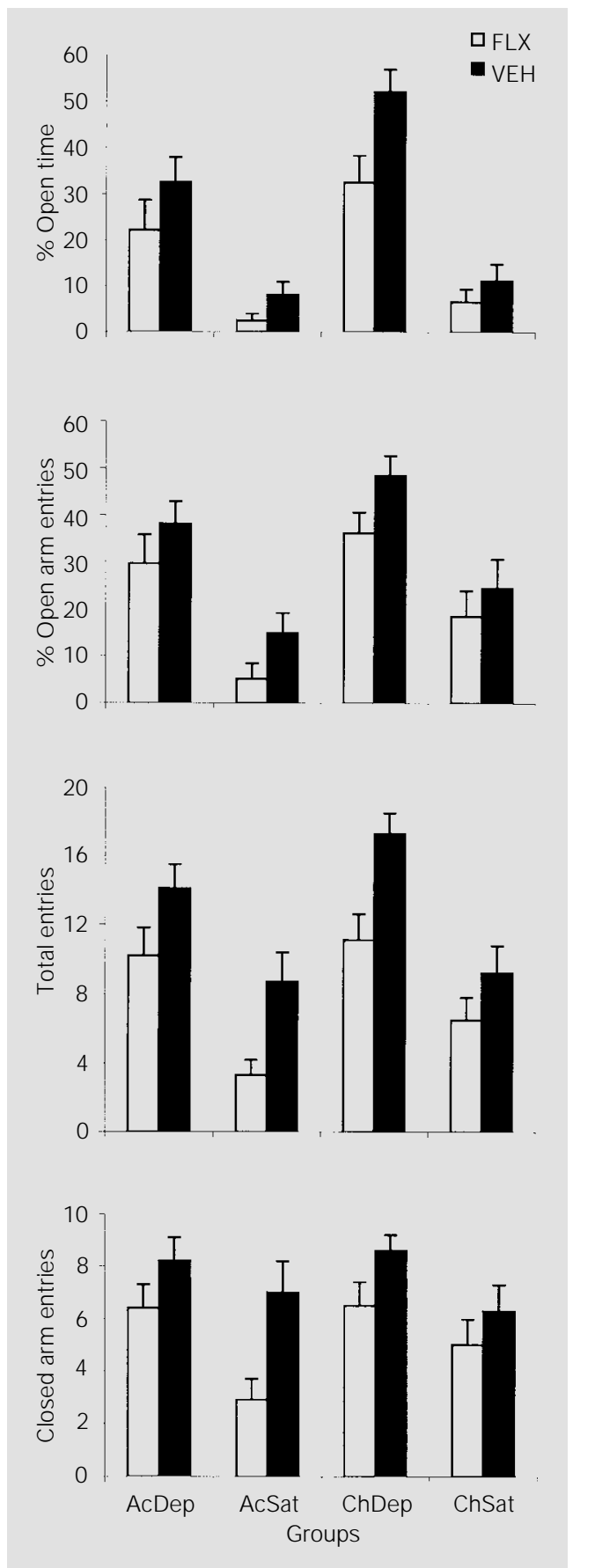

nificant main effect of treatment regimen. The percent of time spent in the open arms was significantly higher in rats submitted to a chronic regimen of either FLX or VEH injections $(\mathrm{F}(1,86)=8.896, \mathrm{P}<0.01)$, as also was the percent of open arm entries $(F(1,86)$ $=7.362, \mathrm{P}<0.01)$. The treatment regimen $\mathrm{did}$ not affect total number of entries $(F(1,86)=$ $2.871, \mathrm{P}>0.05)$ or number of entries into the closed arms $(\mathrm{F}(1,86)=0.286, \mathrm{P}>0.05)$. This effect was not related to alimentary condition or treatment regimen.

Changes in average body weight after chronic treatment were not significantly different between FLX and VEH in the satiated food condition. Average ( \pm SEM) body weights for the VEH and FLX groups increased from $309.2 \pm 14.0$ and $306.3 \pm 17.1$ $\mathrm{g}$ at the beginning of the experiment to 357.1 \pm 11.4 and $360.0 \pm 13.3 \mathrm{~g}$ at the end of the experiment, respectively ( $t=0.10$ for initial weight; $t=0.16$ for final weight).

\section{Discussion}

Fluoxetine induced an anxiogenic-like effect in rats tested in the elevated plusmaze: the drug decreased the proportion of open arm time and entries, regardless of whether it was being administered acutely or chronically, and independently of the subjects being food deprived or satiated. Simultaneously it decreased locomotor activity, as indicated by a reduction in the total number of arm entries and the number of closed arm entries. This motor activity reduction by fluoxetine has been observed before $(20,33)$. The anxiogenic-like effect in the plus-maze has also been reported (20-22), but only after acute administration of the drug. In the present experiment both the chronic and the acute regimen of administration resulted in an anxiogenic profile.

The observed anxiogenic effect after both acute and chronic administration can be seen in the light of the classic hypothesis relating 5-HT and anxiety. The anxiogenic effect 
after acute fluoxetine administration could be related to the increased extracellular 5HT around subcortical structures, observed after acute administration of SSRIs. The anxiogenic effect after chronic treatment would be consistent with the desensitization of 5$\mathrm{HT}_{1 \mathrm{~A}}$ autoreceptors and the consequent reduction in their inhibitory effects on raphe activity. It could also be related to the desensitization of $5-\mathrm{HT}_{1 \mathrm{~B}}$ autoreceptors and the resulting decrease in feedback inhibition of serotonin release observed in the chronic condition $(9,14,17)$.

Still, the differential clinical effect of acute and chronic fluoxetine administration would lead to the expectation of a differential effect on the elevated plus-maze indices of anxiety. In fact, an anxiogenic effect of fluoxetine would be compatible with clinical reports of increased anxiety during the first days of drug administration (34), but would not be consistent with its growing use in the chronic treatment of anxiety disorders (4). As the symptoms of anxiety disorders are heterogeneous and multidetermined, it is possible that the elevated plus-maze model is not sensitive to the specific anxiety symptoms that show clinical improvement with chronic fluoxetine. The main criterion for the use of the elevated plus-maze as an animal anxiety model is its sensitivity to the anxiolytic action of benzodiazepines, but it is known that several anxiety disorders, such as phobias and panic, are resistant to benzodiazepines (35). It is possible that the cat odor test for phobia (36), or the polydipsia model for the obsessive compulsive disorder (31), for example, would be able to detect an anxiolytic action of chronic fluoxetine in the rat.

The possibility that the plus-maze results reported here reflect motor effects of the drug cannot be discarded. As noted, motor activity reduction after fluoxetine administration has been reported. The effect of fluoxetine in the present experiment may have been confounded by changes in motor be- havior, as there was a decrease in the total number of arm entries and in the number of entries into the closed arms, a reliable index of locomotor activity in the elevated plusmaze (37). A model that evaluated both passive and active avoidance, such as the elevated T-maze, would help in dismissing this possibility (38).

Although fluoxetine has been reported to produce decreased appetite and food intake both in humans $(39,40)$ and in rats $(41)$, subjects in the present study did not show any changes in body weight after 22 days of fluoxetine administration. The loss of appetite resulting from fluoxetine treatment would suggest caution in dealing with anorexic patients, since although the target of the prescription are emotional effects, the drug can cause concomitant body weight loss (39). However, there was no evidence of any interaction between fluoxetine and food deprivation on the plus-maze effects within the parameters of drug administration and food restriction used. There was, however, a marked effect of food deprivation on the indices of the plus-maze: food-deprived animals showed a marked increase in proportional open arm entries and time, and in the number of total entries and the number of entries into the closed arms. The elevated plus-maze, as an exploratory model of anxiety, relies on the conflict between the tendency to explore a novel environment and the tendency to avoid open spaces $(42,43)$. Food deprivation increases the probability of foraging responses, and this factor, rather than anxiety reduction, could account for the high locomotor activity and the increased tendency of food-deprived rats to enter and remain in the open spaces in this experiment. On the other hand, the chronic treatment regimen resulted in an anxiolytic profile that was not confounded by locomotor activity. In fact, daily injections of either drug or vehicle resulted in subjects scoring proportionally more time and more entries into the open arms when compared to acutely in- 
jected subjects. Their total number of entries and number of entries into the closed arms, however, were not significantly different, lending support to the hypothesis of an anxiolytic effect. This effect probably resulted from the routine handling necessarily involved in the injection procedure, a factor known to lead to reduced anxiety as measured in the elevated plus-maze and other anxiety paradigms $(44,45)$.

The present results show the anxiolytic action of handling and suggest an anxiogenic action of both acute and chronic fluoxetine on animals tested in the elevated plus- maze. The anxiogenic action of fluoxetine is consistent with the neurochemical effects of the drug on the serotonergic system. These findings, however, should be extended to other anxiety models and to other doses of the drug, especially regarding the chronic procedure, since lower doses might have effects on anxiety-related measures but not on activity parameters.

\section{Acknowledgments}

The authors thank Dr. Emma Otta for advice on statistical analysis.

\section{References}

1. Goldstein DJ , Wilson MG, Thompson VL, Potvin J H \& Rampey J r AH (1995). Longterm fluoxetine treatment of bulimia nervosa. British J ournal of Psychiatry, 166: 660-666.

2. J enike MA, Buttolph L, Baer L, Ricciardi J $\&$ Holland A (1989). Open trial of fluoxetine in obsessive-compulsive disorder. American J ournal of Psychiatry, 146: 909911.

3. Schneier FR, Liebowitz MR, Davies SO, Fairbanks J, Hollander E, Campeas R \& Klein DF (1990). Fluoxetine in panic disorder. J ournal of Clinical Psychopharmacology, 10: 119-121.

4. Stokes PE \& Holtz A (1997). Fluoxetine tenth anniversary update: the progress continues. Clinical Therapeutics, 19: 11351250.

5. Sheehan DV, Ray BA, Trehan RR \& Knapp EL (1993). Serotonin in panic disorder and social phobia. International Clinical Pharmacology, 8: 63-77.

6. Wise CD, Berger BD \& Stein L (1972). Benzodiazepines: anxiety-reducing activity by reduction of serotonin turnover in the brain. Science, 177: 180-183.

7. Iversen SD (1984). 5-HT and anxiety. Neuropharmacology, 23: 1553-1560.

8. Fuller RW \& Wong DT (1987). Serotonin reuptake blockers in vitro and in vivo. J ournal of Clinical Psychopharmacology, 7: 36S-43S.

9. Artigas F (1993). 5-HT and antidepressants: new views from microdialysis studies. Trends in Pharmacological Sciences, 14: 262.

10. Schatzberg AF, Dessain E, O'Neil P, Katz
DL \& Cole J O (1987). Recent studies on selective serotonergic antidepressants: trazodone, fluoxetine, and fluvoxamine. J ournal of Clinical Psychopharmacology, 7: 44S-49S.

11. Cruz APM, Zangrossi J r H \& Graeff FG (1995). Psicobiologia da ansiedade. In: Rangé B (Editor), Psicoterapia Comportamental. Editorial Psy, Campinas, 301-312.

12. Handley SL \& McBlane JW (1993). 5HT drugs in animal models of anxiety. Psychopharmacology, 112: 13-20.

13. Mongeau $\mathrm{R}$, Blier $\mathrm{P} \&$ de Montigny $\mathrm{C}$ (1997). The serotonergic and noradrenergic systems of the hippocampus: their interactions and the effects of antidepressant treatments. Brain Research Reviews, 23: 145-195.

14. Blier $P$, de M ontigny $C \&$ Chaput $Y$ (1987). Modification of the serotonin system by the antidepressant treatments: implications for the therapeutic response in major depression. J ournal of Clinical Psychopharmacology, 7: 24S-35S.

15. Blier $P$, Chaput $Y \&$ de Montigny C (1988). Long-term 5-HT reuptake blockade, but not monoamine oxidase inhibition, decreases the function of terminal 5-HT autoreceptors: an electrophysiological study of the rat brain. Naunyn-Schmiedeberg's Archives of Pharmacology, 337: 246-254.

16. Finley PR (1994). Selective serotonin reuptake inhibitors: pharmacologic profiles and potential therapeutic distinctions. Annals of Pharmacotherapy, 28: 1359-1369.

17. Stanford SC (1996). Prozac: panacea or puzzle? Trends in Pharmacological Sciences, 17: 150-154.
18. Griebel G (1995). 5-Hydroxytryptamine-interacting drugs in animal models of anxiety disorders: more than 30 years of research. Pharmacology and Therapeutics, 65: 319-395.

19. Sánchez C \& Meier E (1997). Behavioral profiles of SSRIs in animal models of depression, anxiety and aggression: are they all alike? Psychopharmacology, 129: 197205.

20. Kshama D, Hrishikeshavan HJ, Shanbhogue R \& Munonyedi US (1990). Modulation of baseline behavior in rats by putative serotonergic agents in three ethoexperimental paradigms. Behavioral and Neural Biology, 54: 234-253.

21. Petkov VD, Belcheva S \& Konstantinova E (1995). Anxiolytic effects of dotarizine, a possible antimigraine drug. Methods and Findings in Experimental and Clinical Pharmacology, 17: 659-668.

22. Handley SL \& M CBlane J W (1992). Opposite effects of fluoxetine in two animal models of anxiety. British J ournal of Pharmacology, 107: 446P (Abstract).

23. Bodnoff SR, Suranyi-Cadotte B, Quirion $R$ $\&$ Meaney MJ (1989). A comparison of the effects of diazepam versus several typical and atypical anti-depressant drugs in an animal model of anxiety. Psychopharmacology, 97: 277-279.

24. Griebel G, Blanchard CD, Agnes RS \& Blanchard RJ (1995). Differential modulation of antipredator defensive behavior in Swiss-Webster mice following acute or chronic administration of imipramine and fluoxetine. Psychopharmacology, 120: 5766. 
25. De Angelis L (1996). Experimental anxiety and antidepressant drugs: the effects of moclobemide, a selective reversible MAO-A inhibitor, fluoxetine and imipramine in mice. Naunyn-Schmiedeberg's Archives of Pharmacology, 354: 379-383.

26. De Vry J , Benz U, Schreiber R \& Traber J (1993). Shock-induced ultrasonic vocalization in young adult rats: a model for testing putative anti-anxiety drugs. European J ournal of Pharmacology, 249: 331-339.

27. Sánchez C (1995). Serotonergic mechanisms involved in the exploratory behaviour of mice in a fully automated twocompartment black and white test box. Pharmacology and Toxicology, 77: 71-78.

28. Griebel G, Rodgers RJ, Perrault G \& Sanger DJ (1997). Risk assessment behaviour: evaluation of utility in the study of 5-HT-related drugs in the rat elevated plus-maze test. Pharmacology, Biochemistry and Behavior, 57: 817-827.

29. Durcan MJ, Lister RG, Eckardt MJ \& Linnoila M (1988). Behavioral interactions of fluoxetine and other 5-hydroxytryptamine uptake inhibitors with ethanol in tests of anxiety, locomotion and exploration. Psychopharmacology, 96: 528-533.

30. Tsuchiya K, Inoue T \& Koyama T (1996). Effect of repeated methamphetamine pretreatment on freezing behavior induced by conditioned fear stress. Pharmacology, Biochemistry and Behavior, 54: 687-691.

31. Woods A, Smith C, Szewczak M, Dunn RW, Comfeldt M \& Corbett R (1993). Selective serotonin re-uptake inhibitors decrease schedule-induced polydipsia in rats: a potential model for obsessive compulsive disorder. Psychopharmacology, 112: 195-198.

32. Muscat R, Papp M \& Willner P (1992). Reversal of stress-induced anhedonia by the atypical antidepressants, fluoxetine and maprotiline. Psychopharmacology, 109: 433-438.

33. Kennett GA, Lightowler S, De Biasi V, Stevens NC, Wood MD, Tulloch IF \& Blackburn TP (1994). Effect of chronic administration of selective 5-hydroxytryptamine and noradrenaline uptake inhibitors on a putative index of 5-HT2C/2B receptor function. Neuropharmacology, 33: 1581-1588.

34. Gorman J M, Liebowitz MR, Fyer AJ , Goetz D, Campeas RB, Fyer MR, Davies SO \& Klein DF (1987). An open trial of fluoxetine in the treatment of panic attacks. J ournal of Clinical Psychopharmacology, 7: 329-332.

35. Graeff FG, Viana MB \& Tomaz C (1993). The elevated $T$ maze, a new experimental model of anxiety and memory: effect of diazepam. Brazilian J ournal of Medical and Biological Research, 26: 67-70.

36. Zangrossi H \& File SE (1992). Chlordiazepoxide reduces the generalised anxiety, but not the direct responses, of rats exposed to cat odor. Pharmacology, Biochemistry and Behavior, 43: 1195-1200.

37. Cruz APM, Frei F \& Graeff FG (1994). Ethopharmacological analysis of rat behavior on the elevated plus-maze. Pharmacology, Biochemistry and Behavior, 49: 171-176.

38. Viana MB, Tomaz C \& Graeff F (1994).
The elevated T-maze: a new animal model of anxiety and memory. Pharmacology, Biochemistry and Behavior, 49: 549554.

39. Ferguson J M \& Feighner J P (1987). Fluoxetine-induced weight loss in overweight non-depressed humans. International J ournal of Obesity, 11 (Suppl 3): 163-170.

40. Wilcox J A (1987). Abuse of fluoxetine by a patient with anorexia nervosa. American J ournal of Psychiatry, 144: 1100.

41. Wong DT, Reid LR \& Threlkeld PG (1988). Suppression of food intake in rats by fluoxetine: comparison of enantiomers and effects of serotonin antagonists. Pharmacology, Biochemistry and Behavior, 31: 475-479.

42. Montgomery KC (1955). The relation between fear induced by novel stimulation and exploratory behavior. J ournal of Comparative and Physiological Psychology, 48: 254-260.

43. Treit D, Menard J \& Royan C (1993). Anxiogenic stimuli in the elevated plus- maze. Pharmacology, Biochemistry and Behavior, 44: 463-469.

44. Aulich D, Spielhofen J \& Raaijmakers WGM (1974). The influence of adult handling and social isolation on dark preference in albino rats. Animal Behaviour, 22: 987-990.

45. Schmitt U \& Hiemke C (1998). Strain differences in open-field and elevated plusmaze behavior of rats without and with pretest handling. Pharmacology, Biochemistry and Behavior, 59: 807-811. 